\title{
neofilolog
}

\author{
Czasopismo Polskiego Towarzystwa Neofilologicznego \\ ISSN 1429-2173, 2019, NR 52/1, 179-195 \\ http://dx.doi.org/10.14746/n.2019.52.1.13 \\ http://poltowneo.org/
}

\author{
Mirosław Pawlak \\ Adam Mickiewicz University, Kalisz \\ State University of Applied Sciences, Konin \\ https://orcid.org/0000-0001-7448-355X \\ pawlakmi@amu.edu.pl
}

\section{HOW TEACHERS DEAL WITH INDIVIDUAL DIFFERENCES IN THE LANGUAGE CLASSROOM: RESULTS OF A STUDY}

\begin{abstract}
The process and outcome of second or foreign language (L2) learning are mediated by an array of variables, the most important of which are perhaps individual difference (ID) factors (cf. Dörnyei, 2005; Dörnyei, Ryan, 2015; Pawlak, 2012a, 2017a). It is therefore not surprising that such factors have been addressed by hundreds, if not thousands, of studies in the last several decades, and while the foci or methodology of such research have inevitably been subject to change, the role of individual variation in $L 2$ has been taken for granted. Apart from illuminating the role of various ID factors, researchers have also attempted to draw up recommendations concerning how what we know about these factors can inform classroom practice. A question arises, though, about teachers' awareness of different facets of individual variation, the steps they take to capitalize on learners' individuality in providing instruction, and the degree to which they can be expected to successfully deal with ID factors in the classroom. The paper tackles these issues by reporting on a questionnaire study which involved 37 Polish teachers of English at different educational levels. The results indicate that, while the respondents are cognizant of individual differences and address them in teaching practice, their understanding thereof is limited and so are the actions they embark on in this respect.
\end{abstract}

Keywords: individual differences; individualization; learner training; variety in the language classroom

Słowa kluczowe: różnice indywidualne, indywidualizacja, trening ucznia, różnorodność w klasie językowej 


\section{Introduction}

Learning a second or foreign language (L2), whether it occurs in instructed or uninstructed settings, poses a formidable challenge, with the process as well as its outcomes being affected by a host of factors. On the one hand, there may exist huge differences in the nature of access to the target language (TL) in the environment (e.g., in a second or foreign language context) and the nature of instruction that learners receive (e.g., main focus on communication or on the learning of language forms). On the other hand, L2 learning is bound to be moderated by a wide array of linguistic, contextual and individual difference (ID) variables (Ellis, 2010; Pawlak, 2017a), and while all of these factors are important, it is the last group that seems to be of vital significance. When individuals embark on the task of learning an L2, they bring to this endeavor their individuality, which is related, for example, to their cognitive aptitudes, beliefs, motivation, anxiety, learning styles or learning strategies (Cohen, 2010; Dörnyei, 2005; Ellis, 2008; Pawlak, 2012a, 2017a). In consequence, they process the language surrounding them in very different ways, they engage with the instructional options to which they have access to different degrees, and the level of proficiency that they ultimately achieve can vary quite considerably as well.

In light of this, it is not at all surprising that over the last few decades, hundreds, if not thousands, of empirical investigations have been undertaken with an eye to establishing how individual variation can impact the way in which learners approach their language learning and the progress they make in this domain. It should also come as no surprise that specialists have postulated that research findings in the area of individual learner differences should serve as important signposts for pedagogy in a variety of contexts. Ranta (2008: 151-152) writes, for example, that practitioners who are "committed to the principle of learner-centeredness should (...) address not only the reallife goals and learning preferences of students but also their cognitive processing needs. (...) accommodating the aptitude profiles of their learners is one way that teachers can provide instruction that will help their students become the best language learners they can be". Oxford and Lee (2008: 312), in turn, make the point that teachers "must understand the crucial roots of language learning such as age, gender, personality, and aptitude". Also worth mentioning is the conclusion reached by Gregersen and Maclntyre (2014: 244), who comment that by "looking into the kaleidoscope of people in the classroom, taking note of the patterns that are forming and the forces that cause those patterns to change, teachers and learners each can use the information emerging from emotion, cognition and behavior to understand and influence the ongoing stream of activity in the classroom". Although there is 
certainly merit to the expectation that our understanding of the role of ID factors should be harnessed in the service of effective $L 2$ instruction, a crucial question arises as to whether such a link between theory, research and classroom practice can be successfully forged. The present paper seeks to address this vital issue by reporting the results of a study which was intended to explore whether and to what extent $L 2$ teachers are aware of the role of individual variation and take it into account when providing instruction. The first part of the paper will be devoted to a succinct overview of the latest developments in research on individual learner differences while the second will focus on the design and findings of the research project. Finally, an attempt will be made to illuminate whether and how future research on ID factors can be expected to pave the way for more effective instructional practices.

\section{An overview of recent developments in research on ID factors in L2 learning}

The body of research into the role of ID factors in learning additional languages is so vast that a thorough overview of this intricate field surely goes beyond the space that the present paper can possibly afford. Nevertheless, it is feasible to point to some general and highly conspicuous tendencies which are evident in this kind of research and to highlight the most important, recent developments in the empirical investigations of some ID variables. When it comes to the first of these, several clear-cut trends can indeed be seen in empirical investigations on individual variation (see also Pawlak, 2017a). First, as will be demonstrated below, some key ID variables, such as aptitude as well as motivation, have been subject to major reconceptualization since the time when their role in the process of $L 2$ learning began to be investigated. Second, while some factors have fallen out of favor with researchers, good cases in point being gender or learning styles, attempts have also been made to isolate entirely new variables, such as boredom (Kruk, Zawodniak, 2018). Third, research has focused predominantly on variables that may be of little relevance to classroom pedagogy (e.g., aptitude, working memory) and there is scant empirical evidence on how ID factors that are very likely to be relevant (e.g., different learning strategies) moderate the efficacy of instructional options. Fourth, recent years have witnessed a growing impact of complex dynamics systems theories (Larsen-Freeman, Cameron, 2007) on research on individual differences, with the consequence that emphasis has been shifted from examining simple, linear relationships to investigating complex interactions among a host of individual and contextual factors, a phenomenon that is best visible in the case of research on motivation and willingness to communicate (Dörnyei, Maclntyre, Henry, 2013; Maclntyre, Legatto, 2011). Fifth, closely related to the 
previous point, the paradigm shift has also brought with it a change in research methodology, with studies based on data obtained by means of carefully designed questionnaires administered to large populations giving way to empirical investigations that are intended to capture the dynamics and interplay of different ID factors in small groups with the help of a combination of different data collection tools. Sixth, despite trends of this kind, there has also been a realization that in order to fully understand the role of individual variation, it would be imprudent to ignore any line of inquiry. Therefore, there is a need to combine the macro-perspective, as embodied in large-scale correlational studies, and the micro-perspective, as seen in research seeking to tap into the role of contextual and individual factors in real-time, as in naturallyoccurring L2 lessons (cf. Mystkowska-Wiertelak, Pawlak, 2017).

With respect to research findings connected to specific ID variables, the present overview can only be selective, both in terms of the ID variables touched upon and the cutting-edge developments that can be outlined. It is perhaps fitting to start with biological age, the role of which has generated so many misconceptions about L2 learning. In particular, it is clear now that it is more sensible to talk about sensitive rather than critical periods, that the impact of age is meditated by other factors, such as aptitude, motivation, or exposure, and that older learners may in fact have an advantage over younger ones due to their experience, adept application of learning strategies, or the specific goals they envisage for themselves (Cohen, 2010; Pfenninger, 2014; Pfenninger, Singleton, 2017). Another ID variable, the understanding of which has been subject to considerable modification is foreign language aptitude which is no longer considered in terms of Carroll's (1981) original model differentiating between phonemic coding ability, inductive learning ability, grammatical sensitivity and memory. Instead, the notion has recently come to be equated with working memory, in particular the phonological loop and the central executive, which, however, have been tapped in disparate ways in empirical studies (Wen, 2015; Li, 2017). Major advances can also be discerned in the study of motivation which has outgrown basic distinctions between instrumental or integrative, or extrinsic and intrinsic, and is currently most frequently understood in terms of the $L 2$ motivation self-system, which includes ideal L2 self, ought-to self and learning experience (Dörnyei, 2009). In addition, motivation is no longer seen as a static attribute of a learner but, rather, something that is in a state of constant flux, both over the years and in the course of a lesson as well as the tasks and activities it comprises (Pawlak, 2012b). The same can be said about willingness to communicate, defined as "the probability to initiate communication, given choice and opportunity" (Maclntyre, 2007: 567), since research has evolved from early attempts to 
identify its structure to efforts to pinpoint factors responsible for its fluctuations in real time (Mystkowska-Wiertelak, Pawlak 2017a; Pawlak, Mystkowska-Wiertelak, Bielak, 2016). There has also been an evident increase of interest in the contribution of emotions to $L 2$ learning, not only the primarily negative ones, such as anxiety (e.g., Gkonou, Daubney, Dewaele, 2017), but also, thanks to the increasing influence of positive psychology (Maclntyre, Mercer, 2014), also the positive ones, such as love, enjoyment or enthusiasm (e.g., Dewaele, Alfawzan, 2018; Gabryś-Barker, 2014; Pavelescu, Petrić, 2018). It is fitting as well in this section to mention language learning strategies which have been criticized on a number of fronts, with calls having been made to abandon the construct altogether and replace it with a more general and inclusive concept of self-regulation (Dörnyei, 2005). However, as can be seen in recent state-of-the-art publications (e.g., Griffiths, 2018; Oxford, 2017; Oxford, Amerstorfer, 2017; Pawlak, Oxford, 2018), there are many as yet unexplored avenues in relation to strategies, in particular with respect to specific TL skills and subsystems such as grammar, pronunciation, pragmatics (see e.g., Pawlak, 2018; Pawlak, Szyszka, 2018). Obviously, all these issues can be investigated both from a macro- and micro-perspective, also taking into account the tenets of dynamic systems theories.

It also makes sense at this point to refer to the ID factors that have only recently attracted the attention of researchers in the domain of $L 2$ acquisition. One of those is boredom which has been investigated in the field of educational psychology but only in the last few years has begun to be considered as a factor mediating the process of learning additional languages. Even though this attribute may be at first blush regarded as the flipside of motivation, it is in fact distinct from it, not least because highly motivated learners may experience different levels of boredom in class and those who are overall demotivated may still take an interest in a particular task or activity (e.g., Kruk, Zawodniak, 2018). On the opposite side of the spectrum, researchers have started looking into the role of curiosity in L2 learning as a separate construct as well, showing that this attribute is positively related to willingness to communicate and enjoyment and at the same times correlates negatively with anxiety (Mahmoodzadeh, Khajavy, 2018). Yet another newcomer in research on ID variables in L2 learning is grit, understood as perseverance and passion for attaining long-term goals (Duckworth, Peterson, Mathews, Kelly, 2007). While the study by Yamashita (2018) failed to find a clear-cut link between L2 grit and achievement in learning Japanese, there are grounds to assume that the construct has considerable potential in explaining the outcomes of language learning, perhaps with the aid of novel data collection instruments. New avenues have also been opened up in the case of individual differences 
among teachers, a good example being the study of language teacher immunity, a quality which allows practitioners to withstand the taxing challenges they are constantly faced up with in classrooms (Dörnyei, Hiver, 2017). Hiver (2017), for instance, demonstrated with the help of retrodictive qualitative modeling that this attribute is related to how teachers function on the psychological, emotional and cognitive levels, and that it helps them successfully adjust to the everchanging exigencies of $L 2$ instruction. The emergence of all these cutting-edge lines of inquiry appears to indicate that, despite all the reservations concerning the future of ID research, the domain is robust and holds considerable promise for explaining the process of $L 2$ acquisition. This said, a crucial question arises concerning the extent to which research findings in this area are likely to make a valuable contribution to everyday teaching practice. This goal could be accomplished, for example, by striving to modify to a certain extent learners' individual profiles (e.g., through promoting style-stretching, offering strategies-based instruction, lowering anxiety), making an effort to match instruction to individual characteristics, as is the case with aptitude-treatment interaction, or simply varying the instructional procedures employed (cf. Biedroń, Pawlak, 2016; Gregersen, Maclntyre, 2014). Whether and in what ways teachers engage in practices of this kind are issues that were the focus of the study reported below.

\section{The study}

\subsection{Aims and research questions}

The aim of the study was to determine the degree to which foreign language teachers in Poland working at different educational levels are cognizant of the role of individual variation in their classrooms and the ways in which they adjust their instructional practices accordingly. More specifically, the following two research questions were addressed:

1. How familiar are teachers with the concept of individual variation?

2. What steps do teachers take to accommodate ID factors in their teaching?

\subsection{Participants}

The participants were 37 Polish teachers of foreign languages employed at different educational levels, the vast majority of whom were females (35 or 94.6\%). Among them, 5 (13.6\%) taught in elementary school, 7 (18.9\%) in junior high school, 16 (43.2\%) in senior high school, and 9 (24.3\%) simultaneously worked at different educational levels, which, as a result of successive reforms, has become commonplace. Thirty-five participants (94.6\%) were teachers of 
English and only two of German. Their average teaching experience equaled 12.57 years and although the range stood at 27 years, the shortest experience amounted to 1 year and the longest to 28 years. In addition, as many as 27 participants (73.0\%) had been working as language teachers for at least 9 years and thus the sample as a whole can be regarded as relatively experienced. Most of the respondents (32 or $86.5 \%$ ) indicated that they regularly participated in workshops intended to enhance their teaching skills, but the type, duration and intensity of such courses varied considerably.

\subsection{Data collection and analysis}

The data were collected by means of a specifically constructed questionnaire which, in addition to items eliciting demographic information, providing the basis for the description of the participants in the previous section, contained seven open-ended queries. They focused on the following issues: (1) the individual differences that the respondents were able to observe among their students, (2) the ways in which the teachers attempted to tap into individual variation (e.g., with the use of existing batteries or questionnaires), (3) the steps the participants took to cater to ID factors in their everyday teaching, (4) the extent to which the respondents strove to modify the individual profiles of their learners (e.g., through strategy training), (5) the ways in which individual differences can be capitalized upon to make instruction more attractive, (6) whether the teachers viewed the existence of individual variation as a problem or as an opportunity to make instruction more effective, and (7) the ways in which the respondents used their understanding of ID factors to help learners find their optimal approaches to L2 learning outside the classroom. In order to encourage more extensive responses and to avoid situations in which some teachers would leave blank spaces due to insufficient TL proficiency, the questions were formulated in Polish, participants' mother tongue, and this was also the language in which they were expected to provide the answers.

The questionnaires were sent out by e-mail to the author's friends and colleagues who were involved in teacher training and could therefore easily access practitioners or were themselves school teachers and could help disseminate the survey. The questionnaires were completed by participants at the time of their choosing electronically or by hand, and were subsequently returned to the researcher. The collected data were subjected to a combination of quantitative and qualitative analysis. The former involved tabulating the numbers of specific responses while the latter focused on the identification of distinct categories and patterns in the answers. In the latter case, since the respondents employed a variety of labels, it was necessary to decide which of those patterns 
or categories a given answer represented, a procedure that was performed with the help of another researcher. Importantly, due to insufficient data, no attempt was made to establish how the participants' responses were mediated by the educational level, gender or teaching experience.

\subsection{Findings and discussion}

The findings will be presented in the same order in which the questions were included in the questionnaire and they will ultimately serve as a basis for answering the research questions formulated for the purpose of the study. When asked to list individual differences that they were able to observe among their students, the participants most frequently pointed to five factors, namely learning styles (21 or $56.8 \%$ ), proficiency (19 or $51.4 \%)$, motivation (16 or $43.2 \%$ ), personality ( 8 or $21.6 \%$ ) and intelligence (6 or $16.2 \%$ ). Other ID variables, such as aptitude, anxiety, gender, strategies, place of residence, family situation, or special educational needs, particularly those related to learning difficulties, were mentioned by one or two respondents. It should be emphasized, however, that the participants employed a variety of labels to describe individual differences. In addition, some of the comments were very brief, imprecise and sometimes even contradictory, which casts doubt on the teachers' genuine understanding of the contribution of specific IDs and may indicate that some of them may have simply regurgitated concepts they remembered from their methodology classes at the university. For example, proficiency was in many cases equated with aptitude or the ability to deal with specific learning tasks, intelligence was conceived of both in terms of general mental abilities and multiple intelligences (Gardner, 1999), motivation was described, among others, as interest, involvement or attitudes, and learning styles were at times conflated with learning strategies. The following excerpts exemplify some of the issues mentioned above: ${ }^{1}$

When working as a teacher, I noticed differences in the ways of learning, the rate of learning vocabulary, proficiency level, motivation, the approach to coping with difficulties, personality and learning styles.

Different levels of involvement and differences in intellectual abilities.

Some learners are visual while others are auditory.

Learners differ with respect to how fast they learn, intelligence, interests as well as their attitude to learning and motivation. They also represent different

${ }^{1}$ All the excerpts have been translated from Polish into English by the present author. 
How teachers deal with individual differences in the language classroom...

learning styles and strategies, they have different family situations, which has an impact on motivation and learning opportunities. I also have many students who suffer from dysfunctions and require individualized instruction.

The situation looks even less optimistic in the case of the procedures that teachers embark on in order to obtain information about individual variation among their learners. For one thing, more than half of the participants (19 or $51.4 \%$ ) openly admitted that they never attempted to embark on this kind of diagnosis. Of those who reported doing so, as many as 13 (35.1\% of the total), stated that such efforts were confined to determining the level of the learners by means of some kind of diagnostic tests, placements tests or simply regular observation in class. A good example is the following comment provided by one of the teachers: "From the first grade I use learners' speech and writing (and later all other forms of evaluating their knowledge, such as tests, answers or compositions) as sources of information about their TL competence and then I compare the results". Only six respondents (16.2\%) stated that they engaged in diagnosing individual variation but only three of those did this by administering questionnaires focusing on learning strategies (e.g., Strategy Inventory for Language Learning, Oxford, 1990), whereas the remaining two in the main focused on learners' needs, interests or learning difficulties, as identified by specialists. One in the latter group wrote: "I use a questionnaire where students assess on a scale from 1 to 5 their interest in the lessons, involvement in class or their diligence and systematicity in completing homework assignments".

The third open-ended query dealt with the steps that the participants took to deal with ID factors in their lessons and all of them reported doing so to a greater or lesser degree. Perhaps somewhat predictably in view of the results reported earlier, efforts in this respect targeted those aspects of individual variation of which the teachers were the most cognizant, although the foci were not exactly the same. The vast majority of the responses (26 or 70.3\%) revolved either in part or in their entirety around catering for the needs of better and weaker learners. This was achieved in a variety of ways, such as, for instance, adjusting the pace of activities to the capabilities of the learners, matching students in different ways during pair and group work activities, assigning tasks at different levels of difficulty or including additional activities for better learners, asking more proficient students to act in the capacity of tutors, or differentiating assessment criteria. Ten respondents $(27.0 \%)$ stressed the importance of variety in addressing individual differences, with some of them stating quite candidly that they are in no position to take into account the individual profiles of all of their students. Seven teachers (18.9\%) reported their attempts to plan and conduct their lessons in such a way so as to ensure comparable 
opportunities for learners manifesting different learning styles. Several respondents also mentioned ways in which they motivated their students or strove to take into consideration learning deficits but these were individual voices, even if examples of procedures applied were quite concrete. Such predominant tendencies are evident in the excerpts provided below:

My requirements are higher for students taking the final exam in English. I also try to allocate additional time to the better ones so that they can prepare for various contests. In class, weaker students are allowed to read their responses while the better ones are encouraged to rely on their memory.

I use songs for auditory learners and pictures or films for those who are visual.

I typically opt for a wide variety of tasks and activities done in the classroom so that everybody can find something for themselves.

All of my students are motivated to get involved in the lesson. The weaker ones are given more time to respond or to complete tasks.

I try to use differentiation when implementing activities and tasks by introducing pair and group work. As a result, less motivated learners can work with those who are highly motivated. Similarly, in such arrangements, more proficient or able students can help those who experience problems.

I do my best to differentiate activities with respect to different skills, paying special attention to learners with special educational needs.

What may come as somewhat of a surprise, as many as 30 out of 37 participants (81.1\%) acknowledged that they set about modifying the individual profiles of their learners. On closer inspection, though, it becomes clear that such attempts were extremely limited in scope and some of the responses indicate that the respondents may simply not have had sufficient grasp of the concept. Nineteen of the teachers (51.4\%) made references to motivating students by, for example, rewarding active participation in class by means of an additional credit, using Internet and computer technology, selecting topics that are of interest to students, organizing pair and group work, praising learners for their performance, providing appropriate feedback or offering encouragement, and bringing interesting people into the classroom. As one participant wrote, "I try to motivate students by assigning additional homework assignments related to students' interests, starting cooperation with schools in other countries (e.g., correspondence, working on joint projects), promoting the use of Internet-based resources". What clearly emanates from the data is that the attempts to foster motivation are quite haphazard rather than principled, drawing, for instance, upon some framework 
of motivational strategies such as that proposed by Dörnyei (2001). Only a handful of teachers (6 or 16.2\%) mentioned taking steps to help students change the strategies they employ, take into account predominant learning styles or adjust instructional procedures to their personalities. Also in this case it was hard to uncover any premeditated plan for effecting changes in individual learner profiles, with the actions described often giving the impression of ad hoc, one-off, reactive measures. There were also a number of comments that can be regarded as clearly irrelevant, such as the following: "Learners have a chance to take part in remedial classes that help them catch up" or "I look for different topics and exercises. We work on projects so that everybody can find something adjusted to their level and abilities". One of the participants who reported her failure to shape ID factors in any way openly admitted that her students at the age of 15 are "reluctant to experience any changes".

In the next question, the respondents were asked whether, as suggested by Gregersen and Maclntyre (2014), they attempt to capitalize on individual variation to make their classes more attractive. Although as many as 30 teachers (81.1\%) stated that they in fact did so, most of the responses were largely repetitions of or elaborations on the practices which they reported using for dealing with ID factors, such as trying to fall back on a variety of instructional procedures or introducing additional tasks. This said, some noteworthy answers were provided as well. One of the teachers wrote, for example, that she tried to use authentic materials such as songs with gaps, short films and videos or different types of games. Another made the following comment: "All learners have their passions and if an opportunity arises to build on this in class, it is always worth it. (...) For example, learners conduct lessons with my assistance, which gives them much freedom and influence on what and how they teach. Sometimes, such lessons are more effective than mine since learners can explain grammar problems in a simpler and more approachable way because they had to learn it themselves and prepare for the class". The respondents who stated that they did not utilize individual variation to enhance the attractiveness of their classes mainly admitted that they did not see how ID factors can be harnessed in this way. One of them wrote: "I know I should build on individual differences to make my lessons more attractive but I do not know how, as this is usually a problem".

Somewhat related to the previous issue was the extent to which the respondents viewed the existence of individual differences among learners as an asset or a liability. Interestingly, a vast majority of the teachers (28 or $75.7 \%$ ) were of the opinion that individual variation had a positive impact on what transpired in foreign language lessons. Some in this group commented that it was "something natural" and therefore had to be dealt with and exploited for the 
benefit of the students. Others offered a wide range of reasons why diverse individual profiles tended to play a positive part by indicating that learners grow by being exposed to learning styles and strategies with which they may have been unfamiliar, they have the opportunity to learn from their more advanced peers, they are more likely to see their strong and weak points, and they are also more motivated to get engaged in the lesson. Another crucial argument was the fact that individual variation was a powerful motivator for the teacher forcing him or her to be more creative, respond to individual needs and invest considerably more effort in preparing lessons. Eight respondents $(21.6 \%)$ admitted that the existence of individual variation simultaneously constituted an advantage and a disadvantage, and the extent to which it benefitted the learners hinges upon a specific situation. In particular, they pointed to the difficulty of dealing with huge differences in TL proficiency, addressing ID factors in large classes, or adeptly capitalizing on them with young learners. Overall, however, one can hardly escape the impression that individual variation was once again mainly viewed in terms of the level of TL proficiency. The following excerpts illustrate some of these points:

Individual differences can have a positive influence on the process of learning. Better students can have an impact on weaker ones and they can motivate the teacher to organize lessons in such a way that both groups are equally involved. Individual differences require more time and attention from the teacher. If they are taken account of, they will always benefit the learners.

Individual variation can have a positive impact on language learning, particularly when students are encouraged to work in groups, share their ideas, etc. However, too extreme disparities in TL proficiency and the pace of learning can diminish the motivation and achievement of the better students.

Individual variation is a fact of life. You just have to identity the differences and adjust your teaching accordingly.

As pointed out by Pawlak (2017b), while capitalizing on learners' individuality may pose a major challenge in the classroom, understanding individual variation may play an essential role in helping students learn more effectively in their own time. With this in mind, the participants were also queried whether they tried to utilize their familiarity with individual learner profiles to optimize the learning process outside the classroom. Also in this case, the results can be seen as quite optimistic since as many as 31 respondents (83.8\%) reported taking some steps in this respect, even if not all of them were always pertinent to ID factors as such. Many teachers wrote that they tried to familiarize learners with strategies for learning vocabulary or grammar, and honing 
different TL skills, others recommended additional materials and in particular Internet-based sources, and there were a few who even held in-class discussions about the best ways of learning and encouraged experimentation in this respect. One of the participants commented: "Most importantly, I try to get learners to look for their learning styles on their own. I suggest using Internet resources. I set up for them a discussion group on Facebook where I put links to useful websites or additional tasks for those who are interested". Another teacher explained: "I request learners who have problems with learning vocabulary to use word cards. Those who experience difficulty with listening are asked to watch films or TV series in English with Polish subtitles".

It is warranted at this juncture to refer back to the two research questions that guided the present study. When it comes to the first of them, it is evident that teachers are at least to some extent cognizant of the existence of individual differences and their impact on the effectiveness of the process of language teaching and learning. The question arises, however, as to the depth of this knowledge and their ability to obtain requisite information about the individual profiles of their learners and here the picture is no longer so optimistic. First, the spectrum of IDs that the respondents mentioned was rather narrow, very few of them went beyond the obvious, such as motivation, styles or strategies, and none made a reference to such crucial variables as beliefs, working memory or willingness to communicate. Second, it is clear from the analysis that the understanding of some of the ID variables was rather superficial, the participants often seemed to just reel off what they remembered from their methodology courses, and there was visible confusion about some factors. Third, perhaps not overly surprisingly, individual variation was very frequently seen as synonymous with different levels of TL proficiency rather than factors typically discussed in the literature. Fourth, mirroring the previous point, diagnosing IDs was mainly confined to determining the differences in the mastery of the language being taught and only a handful of participants tried to tap into strategy use, learning styles or motivating and demotivating factors. Obviously, such a situation must have ramifications for how the teachers actually deal with individual differences, which was the focus of the second research question. On a positive note, it should be stressed that most of the participants take some steps to address individual differences, view them as an ally rather than an enemy and, surprisingly, some of them even report attempts to modify the individual profiles of their learners. It is also clear, however, that most of the reported efforts are directed at catering for various proficiency levels, a finding that is predictable as such differences are immediately visible in the classroom and constitute a real, tangible problem. On the other hand, it would perhaps be unrealistic to expect teachers to do much with 
respect to such factors as aptitude or working memory, mostly because they clearly lack the necessary expertise in this respect. What is undoubtedly optimistic is that the majority of the respondents attempt to build on individual variation outside the classroom. This may be reflective of the fact that they are aware of the inherent difficulty of addressing IDs in the classroom but at the same time realize that making students aware of their styles, strategies or preferred ways of learning may best be taken advantage of in their own efforts to improve the TL.

\section{Conclusions}

The present paper has reported a questionnaire study which aimed to determine the extent to which teachers in Polish schools are familiar with the existence and contribution of individual learner differences and the extent to which they engage in concrete practices to address such factors when providing instruction. While the situation is somewhat more optimistic than could have been anticipated, at least in some respects, it is also obvious that there is a major gap between the research findings regarding IDs and the pedagogical recommendations advanced on their basis, and what teachers actually do on a daily basis in their classrooms. Therefore, there is an urgent need to devise ways in which this gap could be bridged, also keeping in mind that research in some areas, such as working memory, may be less relevant to everyday concerns of practitioners than research in other fields, such as learning styles, learning strategies, communication strategies, motivation, anxiety, beliefs or willingness to communicate (Biedroń, Pawlak, 2016). A crucial caveat is that the study is limited in some important respects, related, for example, to the small number of participants, sole reliance on a questionnaire as a data collection tool, or failure to distinguish between different educational levels. This only goes to show that there is a need for more research on teachers' awareness of individual differences and the ways in which they deal with them in their classrooms because their results might provide scholars with food for thought for their future research endeavors. They are also likely to sensitize researchers to the fact that some ID factors may not be relevant to everyday L2 instruction and that unfeasible pedagogical proposals are only likely to make practitioners even more skeptical about the utility of theories of second language acquisition and the empirical investigations which such theories generate.

\section{REFERENCES}

Biedroń A., Pawlak M. (2016), The interface between research on individual difference variables and teaching practice: The case of cognitive factors 
and personality (in) "Studies in Second Language Learning and Teaching", No. 6, pp. 395-422.

Carroll J. (1981), Twenty-five years of research on foreign language aptitude (in) Diller K. C. (ed.), Individual differences and universals in language learning aptitude. Rowley, MA: Newbury House, pp. 83-118.

Cohen A. D. (2010), Focus on the language learner: Styles, strategies and motivation (in) Schmitt N. (ed.), An introduction to applied linguistics (2nd ed.). London. Hodder Education, pp. 161-178.

Dewaele J.-M.. Alfawzan M. (2018), Does the effect of enjoyment outweigh that of anxiety in foreign language performance? (in) "Studies in Second Language Learning and Teaching", No. 8, pp. 21-45.

Dörnyei Z. (2001), Motivational strategies in the language classroom. Cambridge: Cambridge University Press.

Dörnyei Z. (2005), The psychology of the language learner: Individual differences in second language acquisition. Mahwah, NJ: Lawrence Erlbaum. Dörnyei Z., Hiver P. (2017), Language teacher immunity: A double-edged sword (in) "Applied Linguistics", No, 38, pp. 405-423.

Dörnyei Z., Maclntyre P. D., Henry A. (eds.), 2015. Motivational dynamics in language learning. Bristol: Multilingual Matters.

Dörnyei Z., Ryan S. (2015), The psychology of the language learner revisited. New York, NY: Routledge.

Duckworth A. L., Peterson C., Matthews M. D., Kelly D. R. (2007), Grit: Perseverance and passion for long-term goals (in) "Journal of Personality and Social Psychology", No. 92, pp. 1087-1101.

Ellis R. (2010), Epilogue: A framework for investigating oral and written corrective feedback (in) "Studies in Second Language Acquisition", No. 32, pp 335-349. Gabryś-Barker D. (2014), From failure to failure with enthusiasm (in) "Studies in Second Language Learning and Teaching", No. 4, pp. 301-325.

Gardner H. (1999), Intelligence reframed: Multiple intelligences for the 21st century. New York, NY: Basic Books.

Gkonou C., Daubney M., Dewaele J.-M. (2017), New insights into language anxiety: Theory, research and educational implications. Bristol: Multilingual Matters.

Gregersen T., Maclntyre P. (2014), Capitalizing on language learners' individuality: From premise to practice. Bristol: Multilingual Matters.

Griffiths C. (2018), The strategy factor in successful language learning: The tornado effect. Bristol: Multilingual Matters.

Hiver P. (2017), Tracing the signature dynamics of language teacher immunity: $A$ retrodictive qualitative modeling study (in) "Modern Language Journal", No. 101, pp. 669-699. 
Kruk M., Zawodniak J. (2018), Boredom in practical English language classes: Insights from interview data (in) Szymański L., Zawodniak J., Łobodziec A., Smoluk M. (eds.), Interdisciplinary views on the English language, literature and culture. Zielona Góra: Uniwersytet Zielonogórski, pp. 177-191.

Larsen-Freeman D., Cameron L. (2008), Complex systems and applied linguistics. Oxford: Oxford University Press.

Li S. (2017), Cognitive differences in ISLA (in) Loewen S., Sato M. (eds.), The Routledge handbook of instructed second language acquisition. New York and London: Routledge, pp. 396-417

Maclntyre P. D., Legatto J. J. (2011), A dynamic system approach to willingness to communicate: Developing an idiodynamic method to capture rapidly changing affect (in) "Applied Linguistics", No. 32, pp. 149-171.

Maclntyre P. D. (2007), Willingness to communicate in the second language: Understanding the decision to speak as a volitional process (in) "Modern Language Journal", No. 91, pp. 564-576.

Maclntyre P. D., Mercer S. (2014), Introducing positive psychology to SLA (in) "Studies in Second Language Learning and Teaching", No. 4, pp. 153-172. Mahmoodzadeh M., Khajavy G. H. (2018). Towards conceptualizing language learning curiosity in SLA: An empirical study (in) "Journal of Psycholinguistic Research" (online). https://doi.org/10.1007/s10936-018-9606-3.

Mystkowska-Wiertelak A., Pawlak M. (2017), Willingness to communicate in instructed Second language acquisition. Combining a macro-and microperspective. Bristol: Multilingual Matters.

Oxford R. L. (1990), Language learning strategies: What every teacher should know. Boston: Heinle \& Heinle.

Oxford R. L. (2017), Teaching and researching language learning strategies. Self-regulation in context. London: Routledge.

Oxford R. L., Amerstorfer C. M. (eds.). (2017), Language learning strategies and individual learner characteristics: Situating strategy use in diverse contexts. London: Bloomsbury.

Oxford R. L., Lee R. L. (2008), The learners' landscape and journey: A summary (in) Griffiths C. (ed.) Lessons from good language learners. Cambridge: Cambridge University Press, pp. 306-317.

Pavelescu L. M., Petrić B. (2018), Love and enjoyment in context: Four case studies of adolescent EFL learners (in) "Studies in second Language Learning and Teaching", No. 8, pp. 73-101.

Pawlak M. (2012a), Individual differences in language learning and teaching: Achievements, prospects and challenges (in) Pawlak M. (ed.), New perspectives on individual differences in language learning and teaching. Heidelberg: Springer, pp. xix-xlvi. 
Pawlak M. (2012b), The dynamic nature of motivation in language learning: $A$ classroom perspective (in) "Studies in Second Language Learning and Teaching", No. 2, pp. 249-278.

Pawlak M. (2017a), Overview of learner individual differences and their mediating effects on the process and outcome of interaction (in) GurzynskiWeiss L. (ed.), Expanding individual difference Research in the interaction approach. Investigating learners, instructors, and other interlocutors. Amsterdam - Philadelphia: John Benjamins, pp. 19-40.

Pawlak M. (2017b), Dynamiczny charakter zmiennych indywidualnych - wyzwania badawcze i implikacje dydaktyczne (in) "Neofilolog", No. 48/1, pp. 9-28.

Pawlak M. (2018), Grammar Learning Strategy Inventory: Another look (in) "Studies in Second Language Learning and Teaching", No. 8, pp. 351-379.

Pawlak M., Mystkowska-Wiertelak A., Bielak J. (2016), Investigating the nature of classroom WTC: A micro-perspective (in) "Language Teaching Research", No. 20, pp. 654-671.

Pawlak M., Oxford R. L. (2018), Conclusion: The future of research into language learning strategies (in) "Studies in Second Language Learning and Teaching", No. 8, pp. 523-535.

Pawlak M., Szyszka M. (2018), Researching pronunciation learning strategies: An overview and a critical look (in) "Studies in Second Language Learning and Teaching", No. 8, pp. 293-323.

Pfenninger S. E. (2014), The misunderstood variable: Age effects as a function of type of instruction (in) "Studies in Second Language Learning and Teaching", No. 4, pp. 529-556.

Pfenninger S. E., Singleton D. (2017), Beyond age effects in instructional L2 learning: Revisiting the age factor. Bristol: Multilingual Matters.

Ranta L. (2008), Aptitude and good language learners (in) Griffiths, C. (ed.), Lessons from good language learners. Cambridge: Cambridge University Press, pp. 142-156.

Wen Z. (2015), Working memory and second language learning: Towards an integrated approach. Bristol: Multilingual Matters.

Yamashita T. (2018), Grit and second language acquisition: Can passion and perseverance predict performance in Japanese language learning? Unpublished MA thesis, University of Massachusetts, Amherst, USA. 